\title{
AN IMPLEMENTATION OF 9 PILLARS OF INDUSTRY 4.0 IN CONVENTIONAL FOOTWEAR INDUSTRY MODEL
}

\author{
Suhaib Ur Rehman \\ Department Of Mechanical Engineering \\ Jamia Millia Islamia, New Delhi, India
}

\author{
Shamoil Ejaz \\ Department Of Electronics Engineering \\ Jamia Millia Islamia, New Delhi, India
}

\begin{abstract}
Industrial 4.0, a German term for the trend of intelligent production incorporated with autonomous robots, simulation, horizontal and vertical system integration, IOT, cyber security, cloud computing, augmented reality, big data \& analytic which are interconnected with each other. These interconnected technologies are known as nine pillars of industry 4.0.

In this case study, these 9 pillars were implemented to an existing conventional footwear industry model to transform it into a smart footwear industry model.

Conclusion made from above smart industry model dictates that industrial 4.0, if implemented can increase productivity, revenue, employment opportunities and investments in an industry.
\end{abstract}

Keywords: Interconnected, Intelligent, Industry, Integration.

\section{INTRODUCTION}

The first ever Industrial revolution originated in 18th century with the prime focus to transform the working conditions and atmosphere together with the economy associated with them. As the time gets scaled up, new revolution turned its way to ameliorate the introductory first Industrial revolution.

The first revolution initially aimed to refine textile manufacturing industries by clubbing the small-scale Industries together at a central location to mass scale. The later 18th century saw a major introduction in the first industrial revolution (i.e. Industry 1.0) with the steam and water powered manufacturing facilities being introduced (mechanization), which boosts up the production rate and efficiency in the later 18th century. The continuous development in the mainstream industrial fields initiated the beginning of the second Industrial revolution (i.e. Industrial 2.0) in the early 20th century, which introduced the participation of Electricity as the major pillar of production which enhanced the moderate production to mass production. The late 20th century saw a different form of industrial revolution never seen before i.e. 3rd industrial revolution.

This revolution opened door for electronics and information technology system to achieve a production with improved automation. The introduction of world wide web (WWW), network of networks(internet) and basic computers led to a drastic change in and around the industries and its dependent allies in terms of social, economic and political measures. The 'Industry 3.0' was one of the biggest and rousing evolution of the technological advancement. As 'Industry 3.0' emerge, we saw a drastic escalation in IT and software-based sectors in terms of production, employment and infrastructure which opened the opportunity for further innovations and competitions in these fields. The ascended form of third revolution was the era of digitization which paved way for different paralleled opportunities of capture and value creation. The 3rd revolution allied the basic different technological field of digitization, innovation, verticalization, automation, mechanization and disruptive technology. These paradigm shifts in the industrial production has now paved way for the beginning of 4th Industrial revolution. The term 'INDUSTRY 4.0', firstly introduced and originated in Germany is all about a smart production with smart factories, objects and technology. The future goals are associated with the manufacturing system to be more standard, structured, systematized, cost-effective, energy-saving, streamlined, methodical, well-planned and a system in which products control their own manufacturing process. The 'INDUSTRY $4.0^{\prime}$ ' is a major reminiscence of lined-up software models, a trend towards advanced automation and data exchange together with the participation of cyber physical systems, internet of things, industrial internet of things, cloud computing, artificial intelligence and cognitive computing including machine learning. The basic architecture of this revolution is to construct an environment with less complexity and more efficiency by including the broader concepts of smart factories and smart manufacturing. It aims to work and produce parallelly as per the movement and evolution of the physical world and make decentralized decisions. As the shift in the operative framework has triggered the need for application pull which refers to a pull system for lean manufacturing principle in order to decrease waste in the process of production and offer advantages of optimizing resources, strengthen flow efficiency, more flexibility, resource efficiency and time saving. 




operation once employed to the cloud will allow increased data-driven operations for manufacturing stations.

TIMELINE OF INDUSTRIAL REVOLUTION

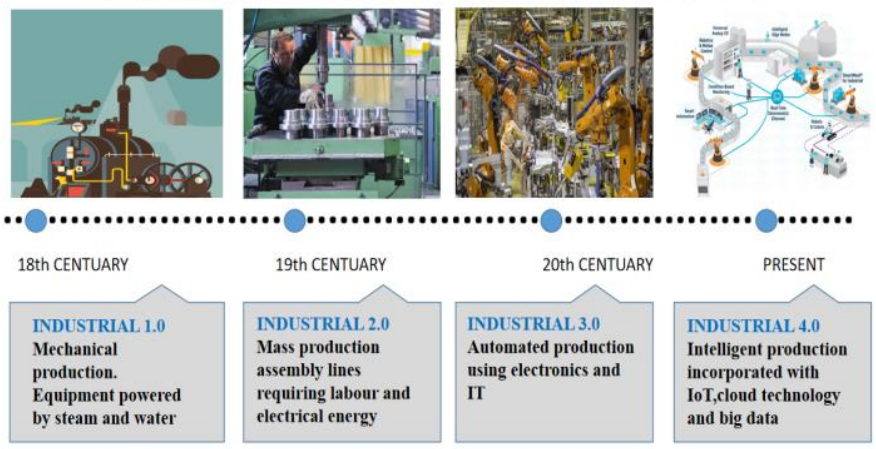

Fig 1. Timeline of industrial revolution

\section{TECHNOLOGICAL ASPECTS}

\section{A. ADDITIVE MANUFACTURING}

Additive manufacturing like 3-D printing are being widely used in Industrial 4.0. They can be used to produce prototypes \& smaller component of machines. Customized, complex and lightweight designs can be achieved. They are widely used by aerospace industry to lighten their aircraft, to reduce fuel consumption.

\section{B. AUGMENTED REALITY}

Augmented reality analyses the existing environment and adds information to it for establishing a new artificial environment. This artificial environment is widely used in industries like healthcare and automotive for real world computer simulations.

\section{AUTONOMOUS ROBOTS}

Since industrial 3.0, robots were widely used to tackle complex assignments, but they are evolving for a greater utility. Robots are becoming more autonomous, pliable and collaborative. They will communicate with each other and work cognitively \& safely with mankind

\section{BIG DATA AND ANALYTICS}

The emergence of large data sets in industries opened way for big data analytic. The focus is to optimize production quality, save power and improvement of equipment and its services. The objective is to garner data from most of the sources involve in the manufacturing and correlating the captured and processed data. Improving failures and customer relations for taking informed business decisions.

\section{E. CLOUD COMPUTING}

In smart factories with increased manufacturing-affiliated operation will require more data sharing across organizations and its employees and customers. System information and its
Various service and product-based companies like Microsoft, Infosys, Google, Autodesk and apple etc have invested in cloud-based technology.

\section{F. CYBER SECURITY}

With the advancement and standardization of cyber technologies, there is a need for protection of information and data. It ensures shielding from theft or provides shelter to overcome damage to the hardware, software and electronic data. The smart industry predominantly based on communication and networking protocols will majorly rely on cyber security for its safety. The system and equipment of an industry are more often under computer-oriented crime and threat.

\section{G. HORIZONTAL AND VERTICAL SYSTEM INTEGERATION}

Boeing, one of the largest manufacturers of aircraft has partnered with Autodesk to facilitate new design using their generative design technology in order to reduce the weight of their aircraft weight and thus increased their fuel efficiency. This is an example of horizontal system integration where a company partners with other company to form out an end to end value chain.

While in vertical system integration company tries to keep as much as value chain under its own banner from designing from product development to its distribution, from designing and manufacturing to its sale and marketing.

\section{H. INTERNET OF THINGS}

The Internet of Things, or IT, refers to the billions of physical devices around the world that are now connected to the internet, collecting and sharing data. With the help of research processors and wireless networks, it's possible to turn anything, from a pill to an aeroplane to a self-driving car into part of the IT. Examples of IT include home automation, self-driving truck, Car2Car Communication, Smart city projects and Smart health tracking devices etc.

\section{SIMULATION}

Every physical problem in a product can be represented in the form of a computational model. This computational model is simulated to reduce the failure in the final product. The need for physical test has been reduce with the embarking of simulation technology.

Simulation techniques like Computational fluid dynamics, Finite Element Analysis, thermal simulation, digital and analogy simulation had saved millions of dollars for industries.

\section{CASE STUDY}

\section{SMART FOOTWEAR INDUSTRY MODEL}




\section{International Journal of Engineering Applied Sciences and Technology, 2020 \\ Vol. 4, Issue 12, ISSN No. 2455-2143, Pages 283-286 \\ Published Online April 2020 in IJEAST (http://www.ijeast.com)}

An existing conventional footwear industry model was taken and different technological aspects of industrial 4.0 was implemented to turn it into a smart footwear industry model. The entire model can be categorized into three parts: Purchasing, Manufacturing and delivery.

\section{A. Purchasing}

Customer will open online portal to select a design. Augmented reality and virtual reality will enable a customer to customize his selection. Final product

details and design will be sent to further department using cloud computation.

\section{B. Manufacturing}

Industrial 4.0 has revolutionized the manufacturing sector. Before fabrication, the designs can be validated by simulating using various simulation packages. With the advent of additive manufacturing, facilities like on-demand manufacturing and customized manufacturing are plausible. The fabricated product will be packed and handle using autonomous robots. IOT, cloud computing, Big data will be used to facilitate, transfer and store shipping details respectively.

\section{Delivery}

Autonomous drone, Kart to Kart communication, self-driving transport services will become prevalent in future to enable a fully automated delivery service. Companies like Amazon and Uber have already started using autonomous drone.

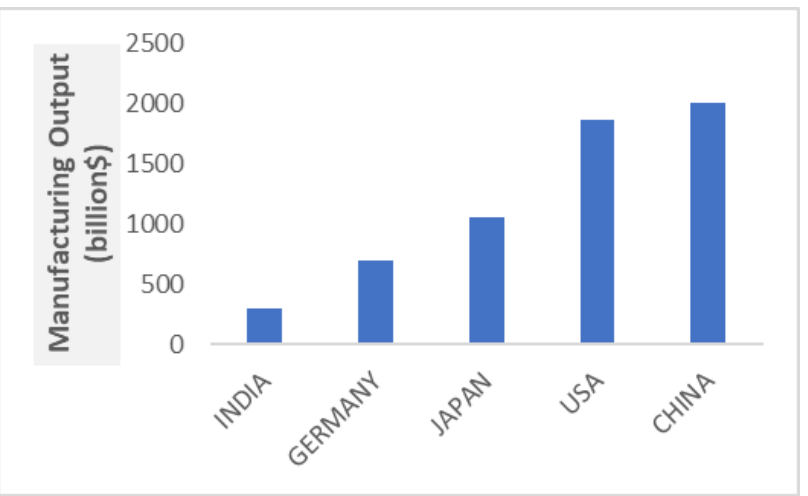

Fig 2. Manufacturing output SOURCE: UN conference 2015

CASE STUDY : IMPLEMENTATION AND PERORATION OF INDUSTRIAL 4.0

CASE : Smart Footwear Industry Model



Fig 3. Smart footwear industry model IV. CONCLUSION

Hence it can be concluded that smart manufacturing or industrial 4.0 will bring boon in four major sectors:

\section{A. Productivity}

Industrial 4.0 is being welcomed by many companies. It is estimated that a 25 to 30 percent increase will be in manufacturing firms. Automotive sectors can expect a growth 10 to 20 percent increase in their production.

\section{B. Revenue growth}

Once productivity of an industry is increased then surely its revenue will grow. It is expected that there will be an additional 1 percent growth in GDP of Germany.

\section{Employment}

There is a misconception that automation and artificial intelligence will steal our job, although it is true that there will be a loss of job, but it is estimated there will be a growth of 5 to 10 percent in jobs in next decade.

However, field like mechatronic engineering, software engineering, communication engineering can expect a further growth in job opportunities.

\section{Investment}

With the adaptation of new technologies like Artificial intelligence, cloud computing, many companies have witnessed a steep rise in seeking new investments.

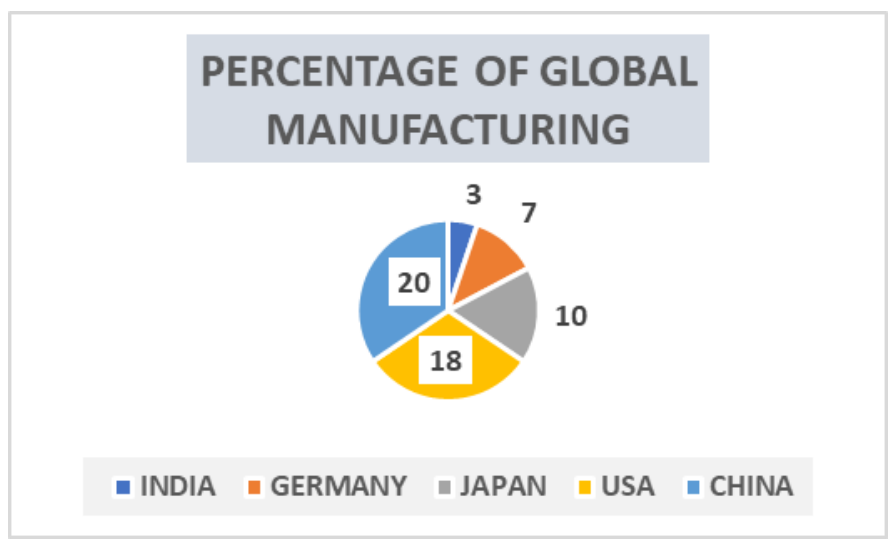

Fig 4. Percentage of global manufacturing SOURCE : UN 2015

\section{ACKNOWLEDGEMENT}

We would like to acknowledge the contribution of our institution JAMIA MILLIA ISLAMIA in providing us the technical equipment and workspace to carry out our research. We would also like thank our colleague and professor for providing us guidance to complete this paper. 


\section{International Journal of Engineering Applied Sciences and Technology, 2020 Vol. 4, Issue 12, ISSN No. 2455-2143, Pages 283-286 \\ Published Online April 2020 in IJEAST (http://www.ijeast.com)}

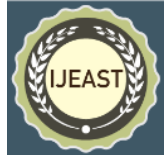

\section{REFERENCES}

[1] Roskill M (2013) Unsickling eider Methodical our dynamistic kontextbasierten Orchestrierung semantischer Feldgerätefunktionalitäten. Technische Universität Kaiserslautern, Kaiserslautern

[2] Lucke D, Constantinescu C, Westkämper E (2008) Smart factory - a step towards the next generation of manufacturing. In: Manufacturing systems and technologies for the new frontier: the 41st CIRP conference on manufacturing systems, Tokyo, Japan,

pp 115-118

[3] Pohlmann EG (2008) Methodik zur prozessorientierten Planung serviceorientierter Fabriksteuerungssysteme. Technische Universität Kaiserslautern, Kaiserslautern Scheer A-W (2012) Industrierevolution 4.0 ist mit weitreichenden organisatorischen Konsequenzen verbunden! Information Management \& Consulting 3:10-11

[4] Wahlster W (2014) Semantic technologies for mass customization. In: Wahlster W, Grallert H-J, Wess S, Friedrich $\mathrm{H}$, Widenka $\mathrm{T}$ (eds) Towards the Internet of services. Springer, Heidelberg, pp 3-13

[5] Lu, Y. (2017). Industry 4.0: A survey on technologies, applications and open research issues. Journal of Industrial Information Integration, 6, 1-10.

[6] Chen, B., Wan, J., Shu, L., Li, P., Mukherjee, M., \& Yin, B. (2018). Smart Factory of Industry 4.0: Key Technologies, Application Case, and Challenges. IEEE Access, 6, 6505-6519.

[7] M.K. Adeyeri, K. Mpofu, T.A. Olukorede, Integration of agent technology into manufacturing enterprise: a review and platform for industry 4.0, in: 2015

International Conference on Industrial Engineering and Operations Management (IEOM), IEEE, 2015, pp. 1-10.

[8] J Albrecht, R. Dudek, J. Auersperg, R. Pantou, S. Rzepka, Thermal and mechanical behaviour of an RFID based smart system embedded in a transmission belt determined by FEM simulations for Industry 4.0 applications, in: 2015 16th International Conference on Thermal, Mechanical and Multi-Physics Simulation and Experiments in Microelectronics and Microsystems (EuroSimE), IEEE, 2015, pp. 1-5.

[9] Ivanov, D., Dolgui, A., Sokolov, B., Werner, F., \& Ivanova, M. (2015). A dynamic model and an algorithm for short-term supply chain scheduling in the smart factory industry 4.0. International Journal of Production Research, 54(2), 386-402. [10] Szirmai, A., \& Verspagen, B. (2015). Manufacturing and economic growth in developing countries, 1950-2005. Structural Change and Economic Dynamics, 34, 46-59.

[11] Rowthorn, R., Coutts, K., 2004. De-industrialisation and the balance of payments in advanced economies. Cambridge Journal of Economics 28 (5),

767-790.

[12] De Vries, J. (1994). The Industrial Revolution and the Industrious Revolution. The Journal of Economic History, 54(02), 249-270.

[13] Industry 4.0 in Big Data environment. German Harting Magazine 2013;26:8-10.

[14] Lee J, Lapira E, Yang S, Kao HA. Predictive manufacturing system trends of next generation production systems. In: Proceedings of the $11^{\text {th }}$ IFAC workshop on intelligent manufacturing systems; 2013. p. 150-6

[15] Christopher Martin (2000), The Agile Supply Chain, "Industrial Marketing Management", V. 29, N. 1, pp. 37-44

[16] Krogh BH. Cyber physical systems: the need for new models and design paradigms. Carnegie Mellon University. p. $1-31$. 